\title{
A new phase for Applied Cancer Research, the official journal of A.C. Camargo Cancer Center
}

\author{
José Vassallo ${ }^{1,2}$
}

It is my great pleasure and honor to announce that Applied Cancer Research entered a new phase and published its first articles in partnership with BioMed Central. Founded in 1975 as Acta Oncologica Brasileira and renamed in 2004 to its current title, the journal has always focused on clinical, surgical and translational research in the field of oncology and values multidisciplinary approaches.

Applied Cancer Research is the official journal of A.C. Camargo Cancer Center, one of the largest cancer hospital in Brazil. Founded in 1953 in São Paulo - the 4th largest city in the world - A.C. Camargo Cancer Center is also a distinguished research and education center in oncology and has partnerships with institutions such as MD Anderson Cancer Center and the International Agency for Research on Cancer.

The growing scientific output, as well as the excellence in patient care that A.C. Camargo Cancer Center has accomplished over the past years, have led the Center to the decision of internationalizing the journal. BioMed Central has been chosen for its pioneering experience in open access publishing in medicine and health sciences.

As a multidisciplinary journal, Applied Cancer Research considers for publication original manuscripts addressing genetics, genomics, pathology, diagnosis, treatment, patient care, and epidemiology. I invite you to submit original research and reviews as well as well exceptionally documented and educative case reports.

The journal editorial board comprises me as Editor-inChief, six Associate Editors, and an international group of 47 experts in the field of oncology [1]. All manuscripts submitted to Applied Cancer Research will be peer-reviewed by one editor and at least two reviewers. The journal is a member of, and subscribes to the principles of the Committee on Publication Ethics (COPE), a forum for editors and publishers to discuss all aspects of

\footnotetext{
Correspondence: vassallomeister@gmail.com

${ }^{1}$ A.C. Camargo Cancer Center, São Paulo, Brazil

2University of Campinas, Campinas, São Paulo, Brazil
}

publication ethics. As a COPE member, we are expected to follow the Code of Conduct for Journal Editors [2].

\section{Benefits to authors}

The partnership with BioMed Central is expected to increase international visibility of the articles published in the journal. Authors should note that, under the CCBY license, they retain the copyright of their work and any third party is allowed to use, reproduce, and disseminate the author's original work, as long as credits are given. The publication costs are currently covered by the A.C. Camargo Cancer Center, so authors do not need to pay an article-processing charge for each article accepted for publication.

We realize how important indexing databases such as PubMed, Web of Science and Scopus are important to authors and our team is highly engaged and working hard to have the journal submitted to those services in the near future, as the journal develops to meet their selective criteria. Applied Cancer Research is already indexed in LILACS, the most comprehensive index scientific and technical literature of Latin America and the Caribbean.

Despite the highly competitive publishing scenario, our conviction is that Applied Cancer Research can make a difference and offer quality content for the oncology community.

I would like to thank A.C. Camargo Cancer Center and our Editorial Board Members for their valuable support. I kindly invite you to keep up to date with the latest articles and welcome your submissions.

\section{Competing interests \\ $\mathrm{J}$ is Editor-in-Chief of Applied Cancer Research and is consultant Pathologist at A.C. Camargo Cancer Center.}

Received: 21 October 2016 Accepted: 25 October 2016 Published online: 24 November 2016

\section{References \\ 1. Editorial Board. [http://appliedcr.biomedcentral.com/about/editorial-board]. \\ 2. Code of conduct and best practice guidelines for journal editors. [http://} publicationethics.org/files/Code\%20of\%20Conduct_2.pdf]. 